\title{
Experimental Studies on the Beriberi Heart
}

\section{Effect of Starvation and Role of Vagus Nerve}

\author{
Yawara YOSHITOSHI, M.D., Nagao SHIBATA, M.D., \\ and Seizo YAMASHITA, M.D.
}

\begin{abstract}
To make clear the mechanism of various electrocardiographic abnormalities observed in thiamine deficient rats, authors have becn carrying on the studies.

In this paper, as our first report on the studies, the effect of starvation and the role of vagus nerve on the electrocardiographic abnormalities are reported.
\end{abstract}

\begin{abstract}
TN our previous paper we have reported our findings such as; appearance of various electrocardiographic abnormalities in the thiamine deficient rats, rapid normalization of those abnormalities by thiamine injection, appearance of right heart enlargement as well as increase of fat granule histologically, and degeneration. The degeneration, believed to be myocardosis, was noticed at the last stage.

Now, the next question that arises is why the various abnormalities due to thiamine deficiency occur in the electrocardiogram. In this paper, as our first report on this question, we shall report on the problems connected with starvation and vagus nerve.
\end{abstract}

\section{Methods}

A. Effect of Starvation.

1. Electrocardiographic examination of gradually underfed rats :

The same amount of basic diet ${ }^{13}$ that the thiamine deficient rats ate was given to normal rats but besides the basic diet, vitamin $B_{1}$ and $B_{2}$ were given in sufficient amount and electrocardiographic recordings on their progress were taken every week.

2. Electrocardiographic examination of unfed rats :

Normal rats weighing $140-150 \mathrm{Gm}$. (4 cases) and $200-220 \mathrm{Gm}$. ( 7 cases) were given only water and enough vitamin $B_{1}$ and $B_{2}$ and electrocardiograms were taken on their progress at intervals of $2 \sim 3$ days.

From the First Department of Internal Medicine, Faculty of Medicine, University of Tokyo, Tokyo. 
3. Histological examination of hearts of the underfed rats:

The rats on the 6th week of underfeeding were slightly anesthetized with ether and then the hearts were quickly taken out. After weighing, the heart was fixed and dyed with Sudan III (S III), Hematoxyline-Eosin (H.E) and PAS.

B. The Role of Vagus Nerve.

Neostigmine $(5 \gamma / 100 \mathrm{Gm}$.) and Atropine sulfate $(5 \gamma / 100 \mathrm{Gm}$.) were injected to thiamine deficient rats every week and thereafter at intervals of every 10 minutes electrocardiographic examinations were taken for about $60 \sim 90$ minutes.

\section{REsulTs}

A. Effect of Starvation.

I. Electrocardiograms of gradually underfed rats.

1. General findings (Fig. 1) :

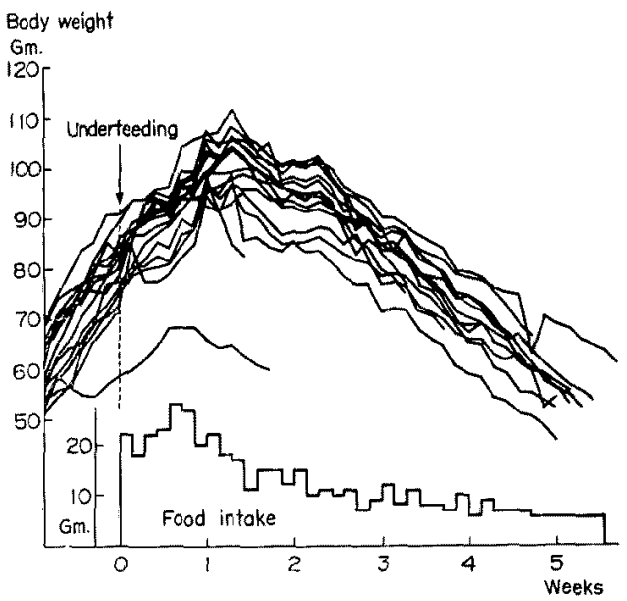

Fig. 1. The progresses of body weight and food intake of underfed rats.

Up to the 7 th to 8 th day of underfeeding, the amount of diet given to the underfed rats was almost enough and they grew the same as the normal rats did. On the 10 th to 12 th day they stopped growing because less amount of diet was given. On the 21 st to $22 \mathrm{nd}$ day there was a definite decrease in the body weight as the amount of diet given them was about $2 / 3$ to $1 / 2$ of their appetite. On the 28 th to 29 th day as the amount of diet was greatly decreased to about $1 / 3$ to $1 / 4$ of their appetite, they ate their one day's food in about 4 or 5 minutes and their body weight dropped greatly. Although they were still lively, 2 of them died. On the 33rd to 35 th day as the amount of diet was greatly decreased to less than $1 / 5$ of their appetite, they ate their one day's food in a very short time and their body weight dropped drastically. Although they 
were still a bit lively 2 rats died. On the 36 th to 38 th day as the amount of one day's food was only 2 or $3 \mathrm{Gm}$. almost all of rats died owing to debility.

2. Electrocardiographic findings (Table I) :

Table I. Electrocardiographic Findings of Underfed Rats

\begin{tabular}{|c|c|c|c|c|c|c|c|c|c|}
\hline \multirow{2}{*}{$\begin{array}{c}\text { Days of } \\
\text { underfeeding }\end{array}$} & \multirow{2}{*}{ Cases } & \multirow{2}{*}{$\begin{array}{c}\text { Body } \\
\text { weight } \\
\text { Gm. } \\
\text { average } \\
\end{array}$} & \multirow{2}{*}{$\begin{array}{l}\text { Case of } \\
\text { arrhyth- } \\
\text { mia }\end{array}$} & \multirow{2}{*}{$\begin{array}{c}\text { Heart } \\
\text { rate } \\
\text { average }\end{array}$} & \multicolumn{3}{|c|}{ Electrical axis } & \multirow{2}{*}{$\begin{array}{c}\text { T mv. } \\
\text { maximum } \\
\text { average } \\
\text { value }\end{array}$} & \multirow{2}{*}{ Remarks } \\
\hline & & & & & Right & Left & Normal & & \\
\hline $7 \sim 8$ & 16 & 99.0 & 0 & 575 & $22.5 \%$ & $\begin{array}{l}4 \\
25 \%\end{array}$ & $\begin{array}{c}10 \\
62.5 \%\end{array}$ & 0.21 & $\begin{array}{l}\text { In all } \\
\text { cases: }\end{array}$ \\
\hline $15 \sim 16$ & 15 & 98.9 & 0 & 557 & $\begin{array}{l}1 \\
6.7 \%\end{array}$ & $\begin{array}{c}8 \\
53.3 \%\end{array}$ & $\begin{array}{c}6 \\
40 \%\end{array}$ & 0.22 & $T_{1}$ : flat \\
\hline $21 \sim 22$ & 15 & 85.4 & 0 & 537 & $\begin{array}{l}3 \\
20 \%\end{array}$ & $\begin{array}{c}5 \\
33.3 \%\end{array}$ & $\begin{array}{c}7 \\
46.7 \%\end{array}$ & 0.19 & $\begin{array}{l}\text { ST: } \\
\text { within } \\
0.1 \mathrm{mv} .\end{array}$ \\
\hline $28 \sim 29$ & 13 & 74.2 & 0 & 525 & $\begin{array}{c}3 \\
23.1 \%\end{array}$ & $\begin{array}{l}1 \\
7.7 \%\end{array}$ & $\begin{array}{c}9 \\
69.2 \%\end{array}$ & 0.22 & $\begin{array}{l}\text { PQ: } \\
\text { about }\end{array}$ \\
\hline $33 \sim 35$ & 11 & 66.8 & 4 & 454 & $\begin{array}{c}5 \\
45.5 \%\end{array}$ & 0 & $\begin{array}{c}6 \\
54.5 \%\end{array}$ & 0.22 & $\begin{array}{l}0.05 \mathrm{sec} . \\
\text { QRS : }\end{array}$ \\
\hline $36 \sim 38$ & 7 & 57.9 & 0 & 469 & $\begin{array}{c}4 \\
57.1 \%\end{array}$ & 0 & $\begin{array}{c}3 \\
42.9 \%\end{array}$ & 0.23 & $\begin{array}{l}\text { within } \\
0.02 \mathrm{sec} .\end{array}$ \\
\hline
\end{tabular}

Table II. Comparison of Electrial Axis

\begin{tabular}{c|c|c|c|c}
\hline Conditions & Cases & Right axis & Left axis & Normal axis \\
\hline $\begin{array}{c}\text { Normal } \\
49.5 \sim 150 \mathrm{Gm} .\end{array}$ & 134 & 10 & 50 & 74 \\
Underfecding & & $(7.5 \%)$ & $(37.3 \%)$ & $(55.2 \%)$ \\
$1 \sim 5$ weeks & 70 & 14 & 18 & 38 \\
Thiamine deficiency & & $(20.0 \%)$ & $(25.7 \%)$ & $(54.3 \%)$ \\
$1 \sim 5$ weeks & 221 & 73 & 45 & 103 \\
& & $(33.0 \%)$ & $(20.4 \%)$ & $(46.6 \%)$
\end{tabular}

Throughout the whole progress there was no change in PQ-interval, QRS-duration, ST-segment and T-wave. After the 5th week there was a slight decrease in the heart rate. On the 33rd to 35th day, a slight sinus arrhythmia was observed in 4 of the emaciated rats. In the electrical axis there were noticed an increase of right axis deviation and a decrease of left axis deviation after the 4 th week, but they were slight in comparison with the thiamine deficient group (Table II).

ERROR CORRECTION :

In our previous report, ${ }^{1}$ there were some numerical errors concerning the description of heart rate. Correct values are as follows:

260-175 (Fig. 11), 300-250 (Fig. 12), 250-200 (Fig. 13), 190-140 (Fig. 14), 246-150 (Fig. 18), 326-283 (Fig. 19) and 391-366 (Fig. 20). 
An example of the electrocardiographic progress is shown in Fig. $2-6$. The body weight began to drop from the 16th day and on the 36th day it dropped markedly to $57 \mathrm{Gm}$. The heart rate fell slightly and on

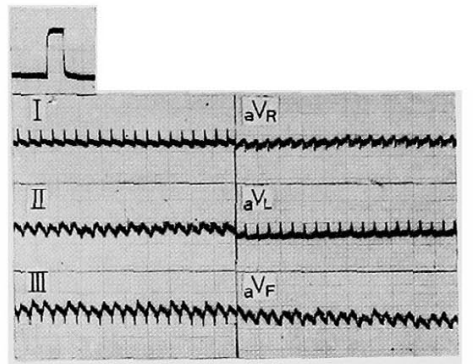

Fig. 2. 8 days of underfeeding, $95 \mathrm{Gm}$., rate 560 .



Fig. 3. 16 days of underfeeding, $86.5 \mathrm{Gm}$., rate 540 .



Fig. 5. 29 days of underfeeding, $69 \mathrm{Gm}$., rate 530 .

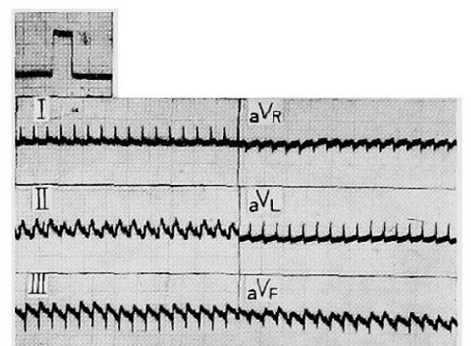

Fig. 4. 22 days of underfeeding, $79 \mathrm{Gm}$., rate 526 .

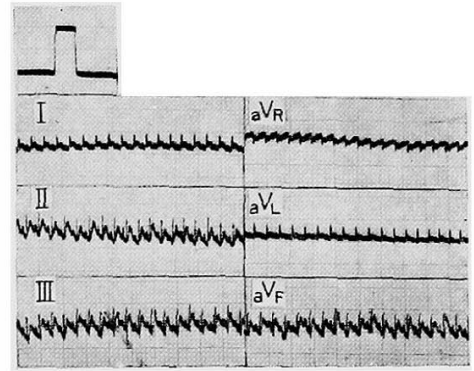

Fig. 6. 36 days of underfeeding, $57 \mathrm{Gm}$., rate 538 .

the 36th day it was 493 but there was no arrhythmia. The electrical axis was left axis up to the 22nd day, on the 29th day it was normal axis and on the 36th day it became right axis. There were no changes in PQ-interval, QRS-duration, ST-segment and T-wave.

The appearance of various great abnormalities in the electrocardiogram just before their death seems to be the usual phenomenon observed in the agonal stage. The abnormalities, such as; extreme bradycardia, heart block and ventricular automatism were observed before the heart 
beat stopped as in general cases. One of the examples is as shown in Fig. 7 and the rat soon died.

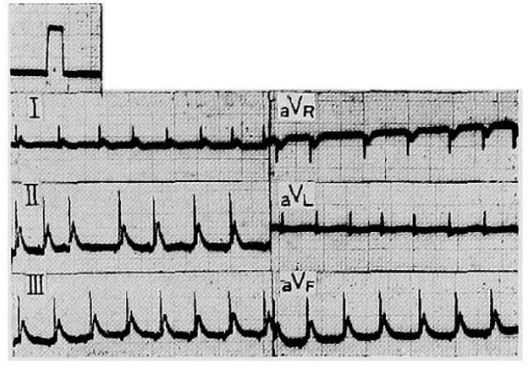

Fig. 7. A case in the agonal stage on the 33 rd day of underfeeding, $67 \mathrm{Gm}$., rate $220 \sim 175$.

II. Electrocardiograms of unfed rats.

1. General findings (Fig. 8):

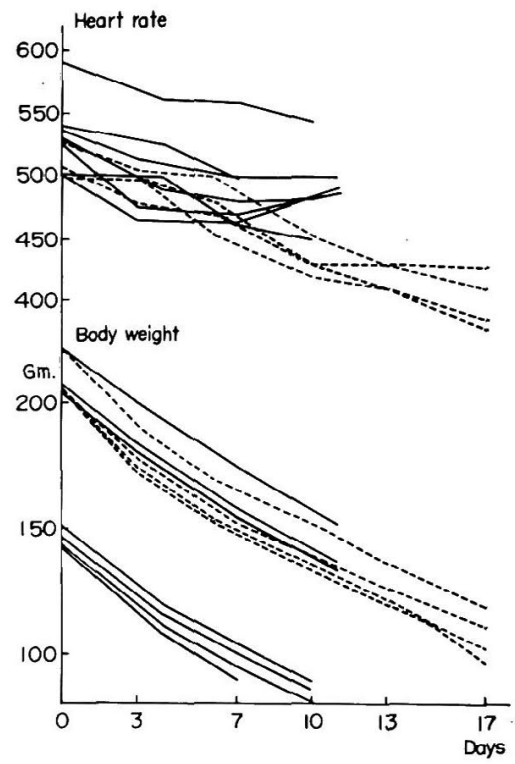

Fig. 8. The progresses of body weight and heart rate of unfed rats.

( - is the group experimented in July)

(... is the group experimented in May)

Without any relation to body weight before starvation, the body weight dropped in a straight line after the beginning of starvation. Rats experimented in May all died in the 2nd week; that is on the 9th day ( 1 case), the 11 th day ( 1 case), the 12th day (2 cases) and the 13 th day (3 cases). Rats experimented in July all died in the 3rd week; that is 
on the 18th day ( 1 case), the 19th day ( 1 case), the 20th day ( 1 case) and the 21st day ( 1 case). In other words those in the warmer season lived longer.

2. Electrocardiographic findings (Table III, Fig. 8) :

Table III. Electrocardiographic Findings of Starved Rats

\begin{tabular}{|c|c|c|c|c|c|c|}
\hline \multirow{2}{*}{$\begin{array}{l}\text { Days of } \\
\text { starvation }\end{array}$} & \multirow{2}{*}{ Cases } & \multirow{2}{*}{$\begin{array}{c}\text { Heart rate } \\
\text { average }\end{array}$} & \multicolumn{3}{|c|}{ Electrical axis } & \multirow{2}{*}{ Remarks } \\
\hline & & & Right & Left & Normal & \\
\hline Before & 7 & 533 & 0 & 3 & 4 & \multirow{4}{*}{$\begin{array}{l}\text { The group experimented } \\
\text { in May. } \\
\text { No change was seen in } \\
\text { electrocardiogram }\end{array}$} \\
\hline $3 \sim 4$ & 7 & 506 & 0 & 3 & 4 & \\
\hline 7 & 7 & 490 & 1 & 1 & 5 & \\
\hline $10 \sim 11$ & 6 & 492 & 3 & 1 & 2 & \\
\hline Before & 4 & 508 & 0 & 2 & 2 & \multirow{6}{*}{$\begin{array}{l}\text { The group experimented } \\
\text { in July. } \\
\text { Except a slight de- } \\
\text { crease in height of T-wave } \\
\text { after the } 6 \text { th day there } \\
\text { was no change in electro- } \\
\text { cardiogram. }\end{array}$} \\
\hline 3 & 4 & 496 & 0 & 2 & 2 & \\
\hline 6 & 4 & 476 & 0 & 1 & 3 & \\
\hline 10 & 4 & 436 & 0 & 1 & 3 & \\
\hline 13 & 4 & 420 & 0 & 0 & 4 & \\
\hline 17 & 4 & 408 & 1 & 0 & 3 & \\
\hline
\end{tabular}

Heart rate dropped just slightly in the group experimented in May, and in the rats experimented in July there was a slight drops in heart rate but no arrhythmia was observed in both groups. In the electrical axis, at the end stage a slight increase of the right axis and a slight decrease of the left axis were observed. However there were no changes in PQ-interval, QRS-duration, ST-segment and T-wave.

An example of the electrocardiographic progress is as shown in Fig. 9-11. Except a slight decrease in heart rate and an increase in the right axis deviation that accompanied progress, there was no change.

The appearance of various great abnormalities in the electrocardiogram just before their death by starvation seems to be the usual phenomenon seen in the agonal stage. The abnormalities, such as; extreme bradycardia, heart block and ventricular automatism were observed before the heart beat stopped as in general cases. One of the examples is as shown in Fig. 12 and the rat soon died.

III. Histological findings of hearts of the underfed rats.

1. Weight of hearts (per $100 \mathrm{Gm}$. of body weight) (Table IV): 


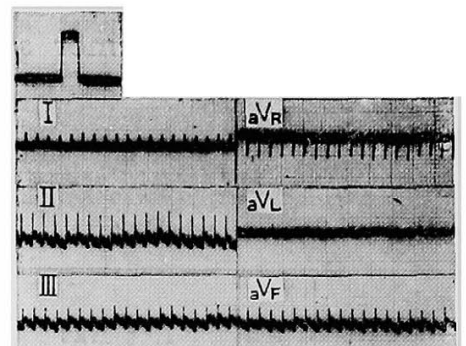

Fig. 9. 4 days of starvation, $105.5 \mathrm{Gm}$., (146.5 Gm. before starvation) rate 566 .

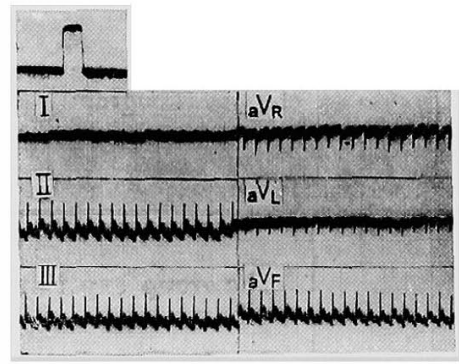

Fig. 11. 10 days of starvation, $86 \mathrm{Gm}$, rate 548 .

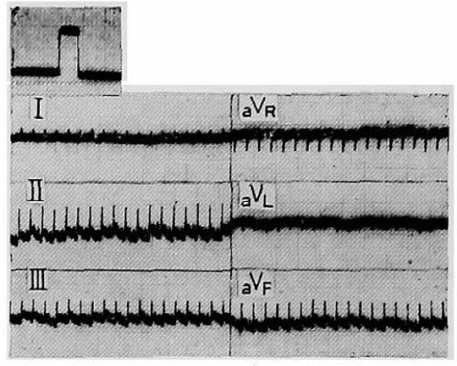

Fig. 10. 7 days of starvation, 100.5 Gm., rate 564 .

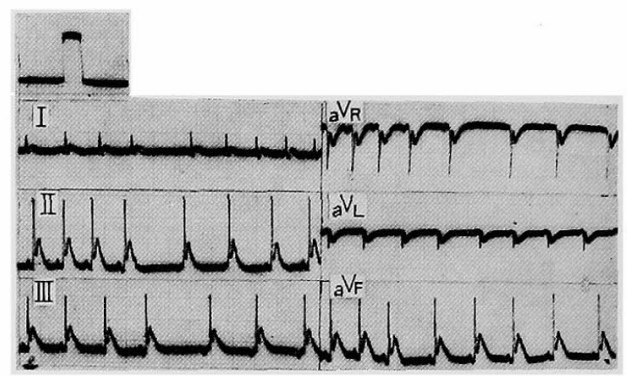

Fig. 12. A case in the agonal stage on the 12 th day of starvation, $74 \mathrm{Gm}$., rate $196 \sim 172$.

Table IV. Comparison of Average Heart Weight (per $100 \mathrm{Gm}$. of body weight)

\begin{tabular}{|c|c|c|c|}
\hline \multicolumn{2}{|c|}{ Condition } & Cases & Heart weight $\mathrm{mg}$. \\
\hline \multicolumn{2}{|c|}{ Normal } & 8 & 398.0 \\
\hline \multirow{5}{*}{ Underfeeding } & 1st week & 2 & 416.5 \\
\hline & 2nd , & 2 & 391.5 \\
\hline & 3rd , , & 3 & 448.3 \\
\hline & 4th , , & 3 & 394.7 \\
\hline & 5 th , , & 3 & 391.3 \\
\hline \multirow{5}{*}{ Thiamine deficiency } & 1st ", & 2 & 405.5 \\
\hline & 2nd, , & 3 & 454.7 \\
\hline & 3rd , & 4 & 438.0 \\
\hline & 4 th , & 8 & 554.0 \\
\hline & 5 th, & 6 & 575.7 \\
\hline
\end{tabular}

No increase of the heart weight was observed in the underfed rats. Compared to the increase in heart weight of the thiamine deficient rats this was very noticeable.

2. Myocardial findings (Table V). 
Table V. Comparison of Myocardial Findings

\begin{tabular}{|c|c|c|c|c|}
\hline \multirow{2}{*}{\multicolumn{2}{|c|}{ Condition }} & S III & H.E & PAS \\
\hline & & Fat granule & Degeneration & Glycogen \\
\hline \multicolumn{2}{|c|}{ Normal } & $\frac{ \pm}{ \pm}$ & - & $\stackrel{+}{+}$ \\
\hline \multirow{3}{*}{ Underfeeding } & 36 th day & - & - & \pm \\
\hline & 37 th day & - & - & - \\
\hline & 40 th day & - & - & - \\
\hline \multirow{4}{*}{ Thiamine deficiency } & 16th day & \pm & $=$ & $\stackrel{+}{+}$ \\
\hline & 23rd day & H & - & + \\
\hline & 30 th day & 世 & $\begin{array}{l}+ \\
+\end{array}$ & + \\
\hline & 41 st day & m & H & \\
\hline
\end{tabular}

In the underfed group no degeneration and increase of fat granule were observed and almost no glycogen was observed in the heart muscle (in the skeletal muscle and in the liver also). The authors believe this is an important finding.

B. The Role of Vagus Nerve.

I. Effect of Neostigmine injection.

Even some of the normal rats died when a large dose of Neostigmine (for instance $20-30 \gamma / 100 \mathrm{Gm}$.) was injected but with a dose of $5 \gamma / 100 \mathrm{Gm}$. hardly any effect was observed.

On thiamine deficient rats, there was a decrease in the heart rate throughout the whole progress when Neostigmine was injected but there was no change in the electrocardiographic complexes. An example is as shown in Fig. 13 where on a rat in the 21 st day of thiamine deficiency,

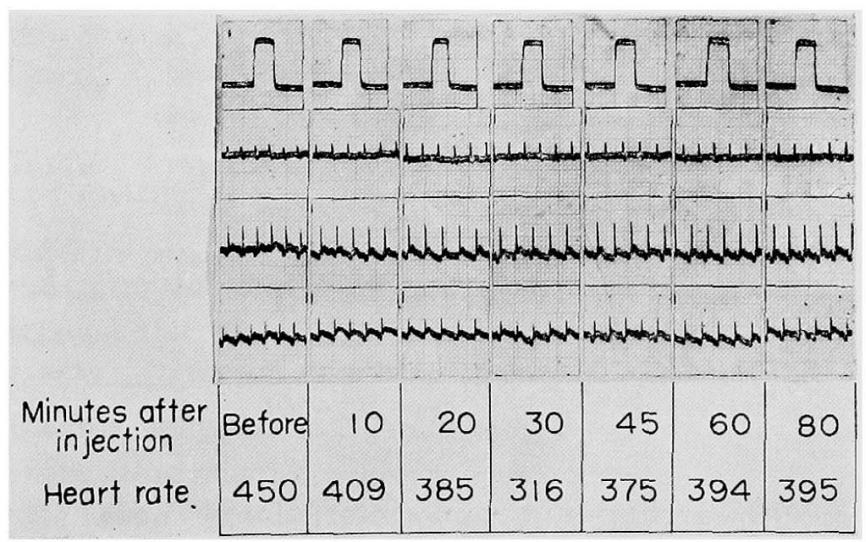

Fig. 13. A case on the 21 st day of thiamine deficiency, $85 \mathrm{Gm}$. 
there was a slight bradycardia but after injection it became worse. The left picture in Fig. 14 shows a slight bradycardia and great elevations of

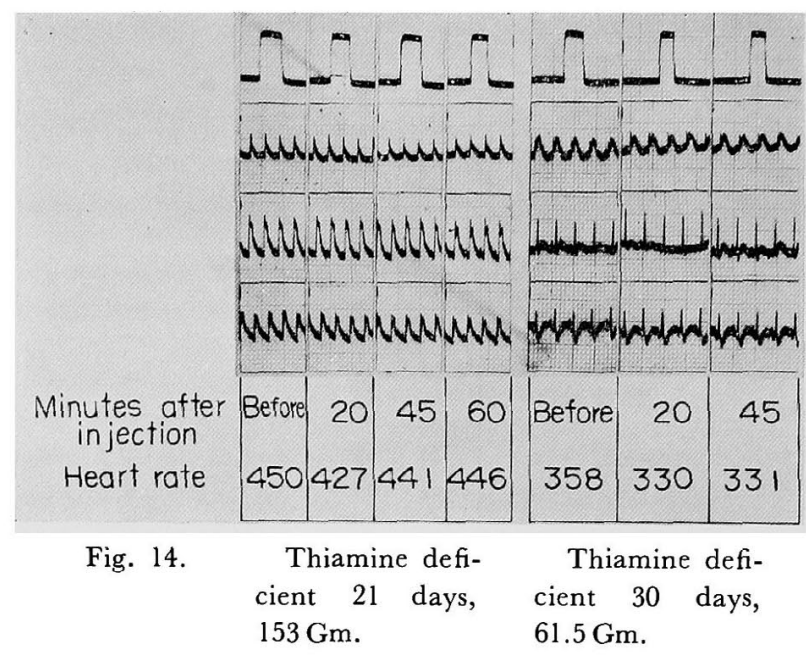

ST-segment and T-wave in a rat on the 21 st day of the thiamine deficiency. The right picture shows bradycardia, elevation of $T_{I}$, flattening of $\mathrm{T}_{\text {II }}$ III and depression of $\mathrm{ST}_{\text {III }}$ in a rat on the 30 th day of thiamine deficiency. After injection, in both cases there were no changes in STsegment and $\mathrm{T}$-wave other than the worsening of bradycardia.

Arrhythmia became worse in almost all cases after injection and in some cases, the normal heart beat became arrhythmical (sinus arrhythmia). An example is as shown in Fig. 15-17 in which bradycardia and

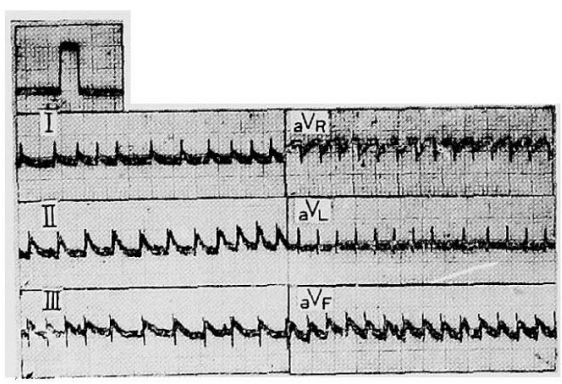

Fig. 15. Before Neostigmine injection, a case on the 30th day of thiamine deficiency, $68 \mathrm{Gm}$., rate $340 \sim 275$.

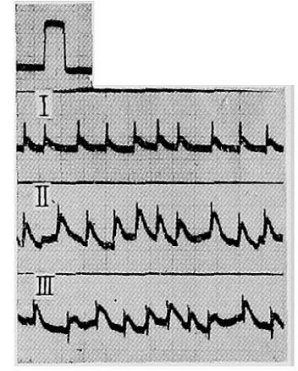

Fig. 16. $20 \mathrm{mi}-$ nutes after injection, rate $283 \sim 250$.



Fig. 17. $80 \mathrm{mi}-$ nutes after injection, rate $326 \sim 300$.

arrhythmia (sinus arrhythmia and interpolated nodal rhythm) were markedly observable on a rat in the 30 th day of thiamine deficiency. 
Arrhythmia and bradycardia started to become worse 10 minutes after injection and they were worst at 30 minutes but after 45 minutes they started to improve and almost recovered after 80 minutes.

Almost all the rats in the agonal stage of thiamine deficiency died about 20 minutes after injection. An example is shown in Fig. 18-21 in which a marked bradycardia, arrhythmia and right axis deviation were observed. Five minutes after injection nodal rhythm appeared and the heart beat stopped after 20 minutes.

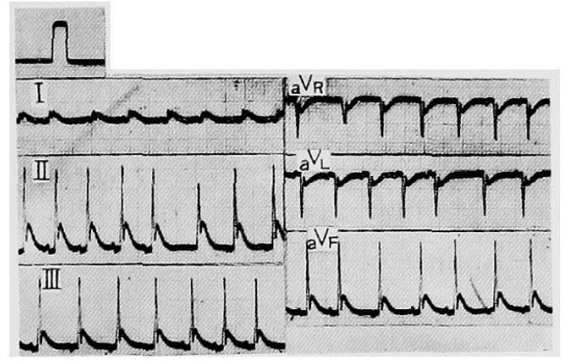

Fig. 18. Before Neostigmine injection, a case on the 27 th day of thiamine deficiency, $73 \mathrm{Gm}$., rate $174 \sim 150$.

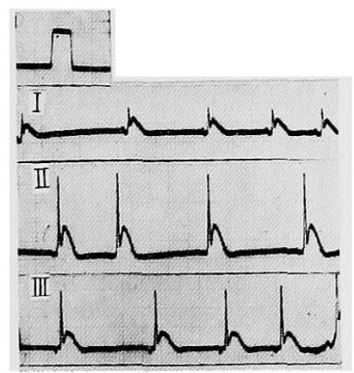

Fig. 20. 10 minutes after injection, rate $88 \sim$ 72.

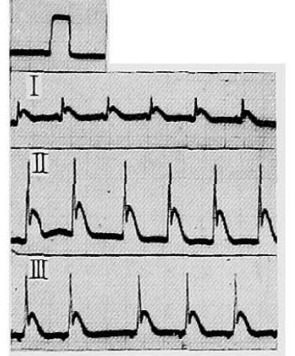

Fig. 19. 5 minutes after injection, rate $130 \sim 107$

II. Effect of Atropine injection.

Among rats on the 2nd to 4th week of thiamine deficiency, in some cases there was a slight increase in heart rate and in other cases there was no increase after injection. In rats after 5th week of thiamine deficiency, no effect on the heart rate was observed. Throughout the whole progress of the thiamine deficient rats the injection showed no effect on electrocardiographic complexes. An example is as shown in Fig. 22 in which there were bradycardia, right axis deviation and $\mathrm{ST}_{\text {II, III depression }}$ on a rat of the 23rd day of thiamine deficiency. After injection, except a slight increase in heart rate, there was no change in complexes of 


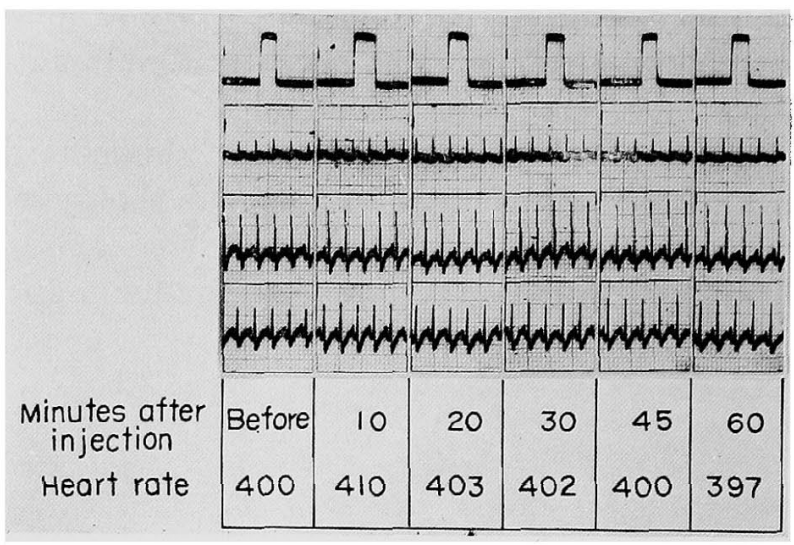

Fig. 22. A case on the $23 \mathrm{rd}$ day of thiamin deficiency, $86.5 \mathrm{Gm}$.

electrocardiogram. Fig. 23-25 show bradycardia, arrhythmia, ST elevation and $\mathrm{T}$ elevation of a rat on the 25th day of thiamine deficiency and showed almost no change after injection.

In most cases arrhythmia showed a marked improvement after injection. Fig. 26-29 are examples of them in which bradycardia and arrhythmia (supraventricular premature beat and sinus arrhythmia) existed in a rat on the 30th day of thiamine deficiency. Arrhythmia started to improve 10 minutes after injection and greatly improved after 30 minutes and after 45 minutes it disappeared. However it reappeared after 80 minutes

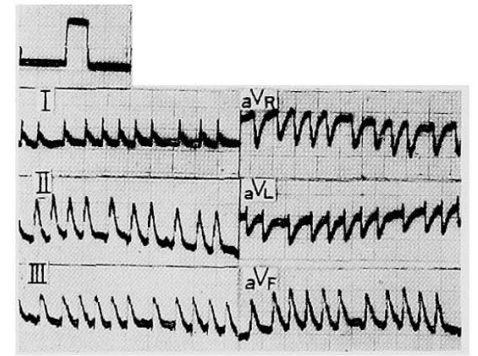

Fig. 23. Before Atropine injection, a case on the 25th day of thiamine deficiency, $104 \mathrm{Gm}$., rate $360 \sim 330$.

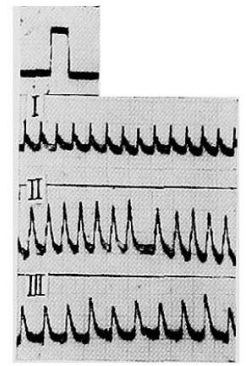

Fig. 24. $20 \mathrm{mi}-$ nutes after injection, rate $380 \sim 340$.

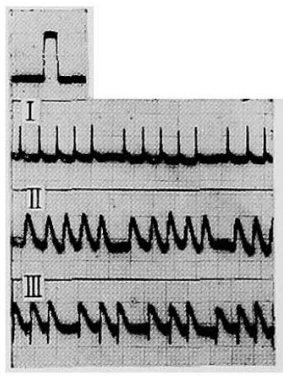

Fig. 25. 50 minutes after injection, rate $336 \sim 314$.

Fig. 30-32 are cases of a rat on the 32nd day of thiamine deficiency in which bradycardia, right axis deviation and arrhythmia (sinus arrhythmia and interpolated nodal rhythm) were markedly observed. But the arrhythmia started to improve 10 minutes after injection and it disappeared after 20 minutes and even after 60 minutes it did not reappear. Contrary to the marked improvement of arrhythmia no effect on the electrocardiographic complexes was seen. 


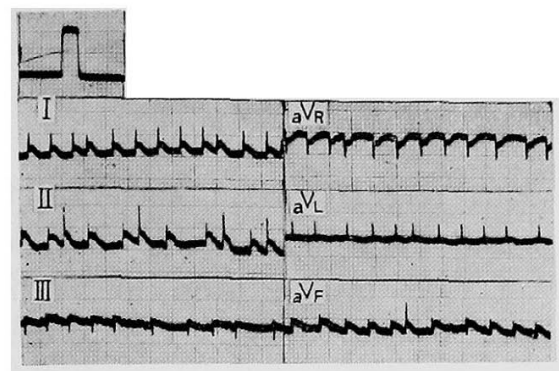

Fig. 26. Before Atropine injection, a case on the 30 th day of thiamine deficiency, $89 \mathrm{Gm}$., rate $326 \sim 250$.

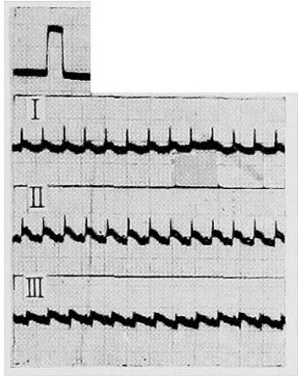

Fig. 28. 60 minutes after injection, rate 326 .

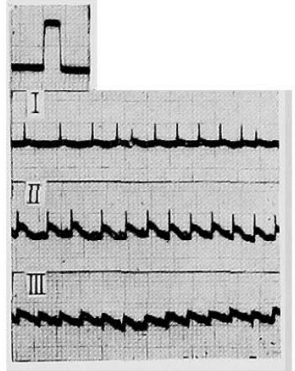

Fig. 27. 30 minutes after injection, rate $326 \sim 300$.

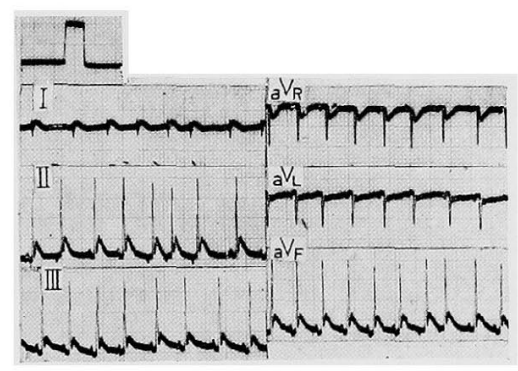

Fig. 30. Before Atropine injection, a case on the 32nd day of thiamine deficiency, $69 \mathrm{Gm}$., rate $250 \sim 200$.

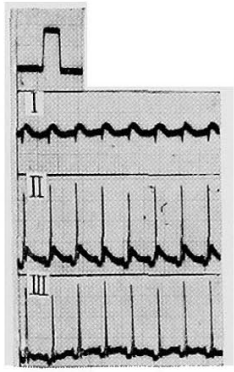

Fig. 31. 20 minutes after injection, rate 246 .

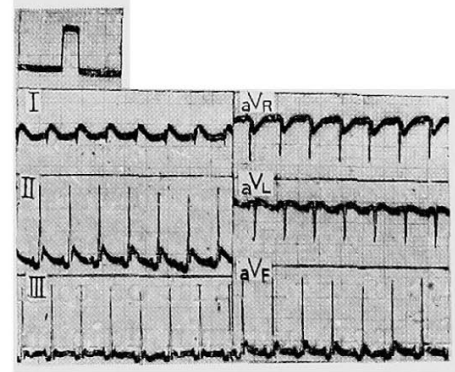

Fig. 32. 60 minutes after injection, rate 242 . 


\section{Discussion}

\section{A. Effect of Starvation}

As we have stated in our previous paper ${ }^{1)}$ when the rats became thiamine deficient their appetite fall and their food intake decrease and at the last stage the daily account of food intake drop to as little as $2 \sim 3 \mathrm{Gm}$., in other words, to a state of starvation. Up to now this problem has often been brought up. ${ }^{2)}$ There are a few opinions ${ }^{3)-5)}$ that the various findings observed in experimental thiamine deficient animals were not on account of thiamine deficiency but due to the attendant starvation. On the other hand, there are reports ${ }^{6)-10}$ ) that cardiac failures were observed in human in condition of undernourishment.

Owing to such differences of opinion we think it is important to make clear whether mere undernourishment or starvation without vitamin deficiency causes electrocardiographic abnormalities. However, there have been almost no electrocardiographic studies made on underfed or unfed rats in comparison with thiamine deficient rats.

As we have stated above, both in the underfed rats and unfed rats, there were no electrocardiographic abnormalities except a slight decrease in heart rate and a slight increase in the right axis deviation observed at the end stage. As such, the authors believe these findings reveal clearly that the various electrocardiographic changes that were observed in the thiamine deficient rats were duc to thiamine deficiency only and not to starvation.

The fact that there was almost no glycogen in the heart muscle (in the skeletal muscle and in the liver also) and no change in the electrocardiogram reveals the existence of body reaction which maintains normal heart function while cousuming the whole source of energy when the rats lack nutritional substance only without thiamine deficiency. In the end the rats died from complete debility, so the authors believe. We believe also that the appearance of various great electrocardiographic changes just before their deaths were the usual phenomena seen in the agonal stage and therefore, it would be unnecessary to consider them as having special significance.

Although there are reports ${ }^{8)-10)}$ that electrocardiographic changes were observed in human malnutrition, in such cases, as these are accompanicd by vitamin deficiencies, the interpretations of these electrocardiographic changes must be considered in the light of under-nutrients (calorie deficiency), vitamin deficiencies and metabolic disturbances.

B. The Role of Vagus Nerve

For a long time it has generally been recognized that tachycardia 
exists in human beriberi ${ }^{11)-20)}$ and it is said that one of the causes is on account of vagus disturbance. ${ }^{11)-18)}$

On the other hand, contrary to human beriberi, bradycardia appears in thiamine deficient animals ${ }^{3)-57,21-31}$ and this difference is the cause of the various opinions.

There are reports ${ }^{21,22)}$ that bradycardia and heart block in thiamine deficient pigeons are on account of overaction of the vagal centers. Contrary to this, there are reports ${ }^{23), 30)}$ that bradycardia of thiamine deficient rats has no relation with vagus. And furthermore there are opinions ${ }^{3)-5)}$ that bradycardia in thiamine deficient animals is on account of starvation.

Owing to such difference of opinions, we carried out studies on the role wich vagus nerve plays in the electrocardiographic changes in thiamine deficient rats.

As stated above, the authors have found worsening of bradycardia and arrhythmia by Neostigmine and improvement of arrhythmia by Atropine and that both injections showed no effect on complexes of electrocardiogram. These findings show that bradycardia and arrhythmia of thiamine deficient rats are related with vagus function but the electrocardiographic complexes are not connected with it.

As such we believe that the difference between the tachycardia of human beriberi and the bradycardia of experimental thiamine deficient animals could easily be explained from our points of view that the tachycardia of human beriberi is on account of vagus hyperfunction and the bradycardia of thiamine deficient animals is on account of vagus hypofunction.

To be sure, the authors do not believe that all bradycardia and arrhythmia are on account of vagal effect but these are to some extent connected with other factors such as disturbance of carbohydrate metabolism owing to thiamine deficiency (a report on this will follow later).

Concerning the mechanism of electrocardiographic abnormalities also a report will follow later.

\section{Summary}

(1) We have studied on the electrocardiogram and the histology of the hearts of the underfed and unfed rats. As we found that there were no electrocardiographic changes and myocardial degenerations in these rats, we believe that there could be no electrocardiographic changes caused by undernourishment (mere calorie deficiency) without thiamine deficiency. In other words, the various electrocardiographic changes which were observed in the thiamine deficient rats were due to thiamine 
deficiency only and not to starvation.

(2) We have studied the vagal effect on the electrocardiographic changes of thiamine deficient rats. Worsening of bradycardia and arrhythmia by Neostigmine injection and improvement of arrhythmia by Atropine were observed but both injections showed no effect on the complexes of electrocardiogram. From these findings the authors found out that bradycardia and arrhythmia of thiamine deficient rats are related with vagus and that the changes of electrocardiographic comprexes are not related with it.

\section{REFERENCES}

1. Yoshitoshi, Y., Shibata, N., and Yamashita, S.: Jap. Heart J. 2: 42, 1961.

2. Sinclair, H. M. : Brit. Med. Bull, 12: 18, 1956.

3. Parade, G.W. : Z. Vitaminforsch. 6: 327, 1937.

4. Parade, G. W.: Z. Vitaminforsch. 7: 35, 1938.

5. MacDonald, D. G.H. and McHenry, E.W.: Arn. J. Physiol. 128 : 608, 1940.

6. Keys, A. et al.: Am. J. Physiol. 150: 153, 1947.

7. Simonson, E. et al.: Am. Heart J. 35: 584, 1948.

8. Ellis, L. B.: Brit. Heart J. 8: 53, 1946.

9. Gillanders, A. D.: Brit. Heart J. 13: 177, 1951.

10. Higginson, J. et al. : Brit. Heart J. 14: 213, 1952.

11. Shimazono, J.: Kakke, Kokuseido, Co., Tokyo, 1927 (In Japanese).

12. Scott, L. C. and Herrmann, G. R. : J. A. M. A. $90: 2083$, 1928.

13. Wenkebach, K. F.: Das Beriberi-Herz, J. Springer Co., Berlin, 1934.

14. Weiss, S. and Wilkins, R.W. : Ann. Int. Med. 11: $104,1937$.

15. Weiss, S.: J. A. M. A. 115: 382, 1940.

16. Blankenhorn, M. A. : Ann. Int. Med. 23: 398, 1945.

17. Blankenhorn, M. A., et al.: J. A. M. A. 131: 717, 1946.

18. Benchimol, A. B. and Schlesinger, P.: Am. Heart J. 46: 245, 1953.

19. Kecfer, C.S.: Arch. Int. Med. 45: 1, 1930.

20. Junco, J. A.: Am. Heart J. 33: 125, 1947.

21. Carter, C.W. and Drury, A. N.: J. Physiol. 68: Proc. i, 1929-1930.

22. Carter, C. W.: Biochem. J. 24: 1811, 1930.

23. Drury, A. N. et al. : Biochem. J. 24: 1632, 1930.

24. Mehes, J.: Arch. Exp. Path. Pharmakol. 176: 141, 1934.

25. Méhes, J. and Péter, F.: Arch. Exp. Path. Pharmakol. 176: 226, 1934.

26. Birch, T.W. and Harris, L. J.: Biochem. J. 28: 602, 1934.

27. Zoll, P. M. and Weiss, S.: Proc. Soc. Exper. Biol. Med. 35: 259, 1936.

28. Baker, A. Z. and Wright, M. D. : Biochem. J. 29: 1802, 1935.

29. Baker, A. Z. and Wright, M. D. : Biochem. J. 33: 1370, 1939.

30. Weiss, S. et al. : Am. Heart J. 15: 206, 1938.

31. Swank, R. L. and Bessy, O. A. : J. Clin. Invest. (abstract) 787, 1940. 